\title{
La España de Franco desde el exterior: el inacabado camino hacia Occidente $(1955-1975)^{*}$
}

\author{
HiPÓLITO DE LA TORRE Gómez \\ Catedrático de Historia Contemporánea. UNED
}

\section{Franco's Spain from an Outward Perspective: the Unfinished Road to Western}

\begin{abstract}
RESUMEN
Este artículo trata de combinar la ya bien conocida evolución política de la España de Franco con las percepciones que generó en las potencias occidentales. El bienio 1957-1959 (guerra de Ifni y colaboración con Francia; reorientación de la política económica) supuso un importante viraje hacia Occidente de la diplomacia de Madrid. El franquismo carecía ya de cualquier alternativa. $\mathrm{La}$ modernización socio-económica lo estaba consolidando, al tiempo que preparaba las bases de un futuro democrático tras la desaparición de Franco. Las potencias democráticas tenían que aceptar la realidad de una España nueva, que ya no era aquella quantité négligeable de los
\end{abstract}

\begin{abstract}
This article tries to combine the wellknown political developments in Franco's Spain and the perceptions generated by these in Western powers. The biennium 1957-1959 (War of Ifni and collaboration with France; reorientation of economic policy) was a major turning point in Madrid's diplomacy towards the West. Franco's regime was already a reality without choice. Socio-economic modernization was backing the dictatorship, while laying the foundations for a democratic future after the Caudillo's demise. The western powers had to accept the reality of this New Spain, which was no longer the quantité négligeable of early days, but whose
\end{abstract}

Reproduzco aquí la introducción que en su día escribí al libro de documentos diplomáticos que coordiné —y en el que participaron Juan Carlos Jiménez Redondo y Rosa Pardo Sanz- sobre la España de Franco, titulado España desde el exterior: la mirada de los otros, Madrid, Editorial Universitaria Ramón Areces, 2011. De nuevo debo recordar que ese libro fue uno de los resultados del Proyecto de Investigación I+D+I, que dirigí (HUM 2006-05302), del Ministerio de Ciencia e Innovación; y también que los documentos norteamericanos fueron gentilmente cedidos por Rosa Pardo. Naturalmente en la mencionada obra se encuentran compiladas las fuentes documentales utilizadas en este artículo. Por último, tratándose de un estudio sobre las percepciones exteriores, y no estrictamente sobre política exterior o relaciones internacionales del franquismo, he omitido toda referencia bibliográfica, que el lector podrá hallar en muchas de las abundantes e importantes obras hasta ahora publicadas sobre política exterior y/o relaciones internacionales de la España franquista. Por su especial utilidad introductoria me limito aquí a registrar la valiosa síntesis coordinada por Juan Carlos Pereira, La política exterior de España. De 1800 hasta hoy, Barcelona, Ariel, 2010 ( $2^{\underline{a}}$ ed.). 
primeros tiempos, pero cuya naturaleza política impedía el pleno desarrollo de todas sus potencialidades exteriores. Entre tanto los poderes occidentales debían ir apostando por el momento de la sucesión.

\section{PALABRAS CLAVE}

España de Franco, modernización económica, relaciones internacionales, potencias occidentales. political hindrances prevented

the full development of its

international potential. Meanwhile, the democracies had to go betting on the succession.

\section{KEY WORDS}

Franco's Spain, Economic

Modernization, International Relation, Western Powers.

\section{LA ILUSIÓN (1955-1962)}

El año 55 tuvo en la historia exterior de la España franquista un hondo significado político y simbólico: con su ingreso en Naciones Unidas, el país salía formalmente de su ostracismo internacional. Ya tres años antes había recibido el fundamental espaldarazo de las «dos espadas», la temporal y la espiritual. Hasta entonces, como la zorra ante las inalcanzables uvas, había despreciado a las decadentes democracias occidentales, débiles para enfrentarse al comunismo, y había buscado afanosamente la amistad — bastante bien lograda - de lo que enseguida vendría a conocerse como Tercer Mundo, además, claro, de la fundamental alianza ibérica, que había funcionado con éxito desde 1936.

Tales amistades, más o menos exóticas, no se habían inventado de la noche a la mañana como «políticas sustitutorias». Si se había echado mano de ellas, era porque había unas tendencias, unas tradiciones, unas orientaciones diplomáticas incluso, de vinculación al mundo árabe y al hispanoamericano, que podían activarse. Esa proyección siempre se mantuvo, y naturalmente sobrevivió al franquismo. Pero es cierto que para las ambiciones y la innegable ubicación españolas, resultaba muy insuficiente. El país había aspirado siempre a un lugar destacado en el concierto de las potencias europeas, y sus ascendientes — pretendidos o realesen escenarios extraeuropeos resultaban sobre todo útiles en la batalla por una posición de respeto entre los poderes occidentales. De modo que, en la medida en que Occidente le abriera sus puertas, la España franquista también occidentalizaría sus querencias y sus objetivos diplomáticos, sus estructuras socioeconómicas y acaso también las políticas.

Esa España de mediados de los cincuenta había dejado atrás la guerra civil, la terrible represión, los indeseables recuerdos de sus amistades con el Eje. La personal y férrea dictadura franquista, era a los ojos del exterior un hecho completamente consumado, irreversible, que podía permitirse ya alguna flexibilidad, cierto aspecto de paternalismo autoritario y civilista. El país había comenzado entre tanto a dar señales de un primer impulso modernizador, al que no resultaban 
ajenos ni la ayuda económica norteamericana, ni el incipiente reblandecimiento de las políticas autárquicas. En la medida en que Occidente se lo permitiera y no envenenara demasiado los valores del régimen, la España de Franco caminaría en esa dirección.

El Occidente apetecido por la diplomacia española era sustancialmente el espacio euroatlántico. Sólo parcialmente los Estados Unidos, cuyas relaciones, demasiado contaminadas por la obligatoriedad y la marcadísima dependencia, tuvieron desde el principio un sesgo de trágala, de modo que el inevitable eje Madrid-Washington, poco apreciado por la opinión española en general y buena parte de los medios políticos del régimen, resultaba en buena medida obligatorio sucedáneo de la genuina vocación europea de España. No era, por tanto, infrecuente que la búsqueda del porvenir español en Europa pudiera también deducirse de expresiones críticas hacia los Estados Unidos.

En 1956 se reflejaba con claridad la encrucijada española. Un informe norteamericano ${ }^{1}$ mostraba la pluralidad de focos de atención de la diplomacia de Madrid, cabalgando entre las tendencias neutralistas y la aproximación a Occidente, aunque se sugería que el aparente predominio de las primeras tuviera el verdadero sentido de «protegerse, maniobrar o negociar» respecto de aquella aproximación.

El apresurado y forzado abandono del protectorado de Marruecos a principios de abril de ese año se había encajado razonablemente bien, pero, aunque el régimen lo hubiera presentado como un paso congruente con su conocida amistad y comprensión hacia la realidad del mundo árabe, no por ello había dejado de constituir un contratiempo en su agenda histórica arabista.

En los meses siguientes, las crisis de Suez y de Hungría vinieron a acentuar el desencanto español. Ambas habían dejado la huella de un cierto desengaño que, a su vez, contribuía a aproximar a España a las potencias euroccidentales. Había fracasado la tentativa de la diplomacia de Madrid de desempeñar un papel de mediación en la crisis del Canal. A los egipcios les importaba el apoyo norteamericano, no el español. Cuando se desencadenaron las operaciones militares, el gobierno - suponía el embajador francés— había acabado por unirse a la opinión en apoyo de Londres y París. Al régimen le resultaba incomprensible que los Estados Unidos se asociaran a la URSS contra las potencias occidentales. Afloraron entonces los sentimientos antiamericanos, reforzados por la inhibición de Washington en la coetánea crisis de Hungría, que había permitido campar por sus respetos al rodillo comunista. Las dos crisis habían hecho surgir en España - según suponía el diplomático francés- un «sentimiento europeo auténtico de solidaridad»: con Francia e Inglaterra, en la primera de ellas; con Hungría, en la segunda. España necesitaba a los Estados Unidos, sobre todo debido a la crisis

1 EAM a SE, 4.I.1957 (NARA, RG59 Decimal Files, 1955-1959, 652.00/1-457). 
económica que se agravaba, pero sus sentimientos despertados eran europeos. «Con cierta torpeza, debida a la vez a su orgullo y a su inexperiencia, España parece capaz de interesarse por todos los esfuerzos que se desplegarán a favor de la creación de una comunidad europea y de aportar una contribución que no deberíamos rechazar»².

El cambio de gobierno de febrero de 1957, con la entrada de los primeros ministros tecnócratas dispuestos a modernizar la administración y la economía, y la llegada a Exteriores del dinámico Fernando Castiella, había venido a imprimir un fuerte impulso a la orientación occidentalista y europea de la política internacional española. El embajador francés descubría en el ministro español no sólo un declarado sesgo europeísta, sino también antiamericano. Creía que las crisis de Suez y de Hungría, así como la excesiva contemporización del presidente Eisenhower con el adversario soviético, estaban dejándose sentir en las posiciones de la diplomacia española. Y revelaba una anécdota significativa: en un vuelo de inspección a las bases, el embajador estadounidense había oído perplejo al ministro Castiella «que dichas instalaciones sólo serían realmente eficaces si España perteneciera a la OTAN», extendiéndose «en recriminaciones sobre la debilidad de los Estados Unidos, que no habían intentado vencer la hostilidad de algunos de sus aliados a dicha admisión. Luego subrayó que era necesario que Europa se liberase de toda tutela, política y económica, de los dos bloques enfrentados». El hispanófilo Lodge, «no salía de su asombro»3.

Pero la clave del giro pro europeo de la política exterior española estaba en las objetivas dificultades del cacareado escenario de la amistad con el mundo árabe. A finales de 1957 un lúcido despacho del embajador del Reino Unido daba cuenta de las repercusiones de los ataques marroquíes (encubiertos bajo el sello del incontrolado Ejército de Liberación) contra las posesiones aún conservadas por España en el noroeste africano. Se había tornado necesaria la colaboración con Francia para conservar Ifni, mientras que hubo de entregarse Tarfaya un año después de haberse desalojado la zona española del protectorado. Fue un nuevo golpe de desencanto con los «amigos» árabes. Madrid estrechaba su solidaridad con el vecino del norte. Ahora ya le comprendía y le apoyaba en su problema de Argelia: las revueltas anticoloniales eran la consecuencia de la nueva táctica de expansión mundial del comunismo, torpemente favorecido por el anticolonialismo de Washington ${ }^{4}$. El alejamiento de Estados Unidos y la aproximación a Europa guardaban entre sí estrecha relación.

Al concluir la década de los años cincuenta, dos importantes documentos de la embajada francesa en Madrid mostraban de forma convincente cómo la política exterior española se había reorientado hacia las posiciones de las potencias de

2 EFM a MAEF, 26.XII.1956 (ADC Europe 1956-1960 Espagne ํㅜ237).

3 EFM a MAEF, 20.VII.1957 (ADC Europe 1956-1960 Espagne no 237).

4 EBM a FO, 19.XII.1957 (PRO FO371-130327). 
Europa occidental, matizando, nunca abandonando, sus conexiones extra-europeas. El giro modernizador de la política económica del franquismo, la notable mejoría de las relaciones con la Francia de De Gaulle - más propicia a atender las tradicionales reclamaciones españolas sobre control de la actividades del exilio antifranquista; receptora, en contrapartida, de la medidas de Madrid contra los activistas de la OAS - y la distensión de las relaciones hispano-británicas, antes de que a la vuelta de unos años volviera a saltar con fuerza el contencioso de Gibraltar, todo ello contribuía a despejar el camino del reencuentro español con los vecinos euroccidentales.

El giro pro-occidental de la política externa española se expresaba con claridad en las declaraciones del ministro del Ejército, general Barroso, al embajador francés a mediados de diciembre de 1959. España, el Caudillo, apoyaban ahora calurosamente la presencia de Francia en Argelia. Madrid siempre había querido servir de puente entre Occidente y el mundo árabe, pero no a costa de un avance del comunismo. Por eso, había tenido que rectificar: «Desde hace mucho — declaraba Barroso- el Generalísimo tenía la convicción o al menos esperaba que España pudiera desempeñar un papel útil ante el mundo árabe, el de intermediario entre Occidente y el mundo musulmán. Pero piensa que esto no se puede hacer en detrimento de Francia en Argelia o de Europa en general en África, en perjuicio de una solidaridad que es más importante y más necesaria que todo lo demás. El continente africano se encuentra actualmente amenazado en su conjunto por todas las fuerzas del comunismo y de la subversión. Es un hecho que hemos tenido que constatar, y que ha supuesto un auténtico giro en nuestra política».

La idea de un Pacto Mediterráneo continuaba siendo fundamental; reflejaba esa constante voluntad de intermediación española entre Europa y el mundo islámico, pero ahora adquiría una matiz occidentalista: Barroso lo circunscribía al Mediterráneo occidental (incluyendo, además de España, a Italia y Francia, a Túnez y Marruecos) y lo contemplaba como complemento/proyección mediterránea del sistema de seguridad occidental; complemento, por tanto, de la Alianza Atlántica, abriendo así una interesante vía de incorporación regional a España. El embajador francés había reforzado los planteamientos de su interlocutor, recordando muy intencionadamente que había sido Francia la en su día presionara a Italia a entrar en OTAN, para equilibrar asimismo el excesivo peso de los países del norte. Y lo más significativo era que el diplomático galo estaba seguro de que Barroso era tan sólo el portavoz de las ideas de Franco, que, su juicio, tenían ahora toda la consistencia de verdadera «doctrina» exterior ${ }^{5}$.

Pocos días después - finales de diciembre - Castiella daba cumplida cuenta al embajador de Francia de la entrevista entre Franco e Eisenhower. El Caudillo habría alertado al presidente norteamericano de la amenazadora vía de expan-

${ }^{5}$ EFM a MAEF, 18.XII.1959, no 1182/EU (ADC Europe 1956-1960 Espagne no 241). 
sión del comunismo mediante el apoyo que prestaba la URSS a los nacionalismos del Tercer Mundo. España temía la infiltración comunista en el norte de África, le inquietaba la desestabilización de Marruecos y apoyaba la política francesa de resistir en Argelia, mientras se tornaba posible un régimen autonómico de vinculación a la metrópoli. Concluía el embajador francés: «Evidentemente, al poner el acento en la agitación sistemáticamente alentada por la URSS y por la China comunista en África, el Generalísimo intentaba tocar una fibra sensible de su interlocutor, y así advertirle contra una política de concesiones prematuras o excesivas respecto a los nacionalismos africanos. Pero su inquietud no es por ello menos real. Se originó hace ya algún tiempo y se ha desarrollado por la presión de las reivindicaciones territoriales marroquíes y la prolongación de la guerra de Argelia. Explica, en gran parte, que el Generalísimo y su gobierno se hayan visto en la necesidad de modificar las perspectivas de su política general y de adoptar poco a poco una actitud análoga a la de Francia respecto a la solución futura del problema argelino. Las declaraciones del general Franco cuando le presenté mis cartas credenciales, las que constantemente me hace el señor Castiella y las que me hizo el 17 de diciembre pasado el ministro del Ejército, van en esa dirección; y no podemos dejar de felicitarnos al constatar que, en su conversación con el presidente de Estados Unidos, el Jefe del Estado español haya defendido quizá más claramente aún unas ideas tan cercanas a las nuestras»6.

La idea de que la ofensiva expansionista de la URSS se concentraba sobre el escenario del Tercer Mundo - lo que distaba de ser una genialidad- estaba firmemente instalada en el Caudillo. De nuevo la expresaba en su entrevista, en mayo de 1961, con el Secretario del Foreign Office, Douglas Home. Había que apoyar a Salazar — decía Franco - en su combate a la insurgencia de Angola; había que neutralizar la expansión comunista en Iberoamérica desde el santuario cubano. El peligro comunista no se cernía tanto sobre Europa como en los países subdesarrollados. La ventaja de la URSS frente a Occidente, se cifraba en que el comunismo poseía una mística y apostaba más fuerte en la ayuda a los países atrasados?.

Esa obsesión por el comunismo y un sentimiento profundo, y nunca desmentido, de solidaridad ibérica, habían llevado a la España de Franco a apoyar la resistencia colonial de la dictadura salazarista. El embajador norteamericano en Madrid creía que el régimen temía sobre todo la caída del salazarismo, que abriría las puertas a un gobierno «de tipo castrista» en Lisboa ${ }^{8}$.

El año 61 escenificaba, efectivamente, el arranque de una intensa ofensiva contra el Portugal de Salazar: Había comenzado con la revuelta de Angola y la captura por opositores ibéricos del DRIL del transatlántico «Santa María»; había

\footnotetext{
${ }^{6}$ EFM a MAEF, 23.XII. 1959, no 1195/EU (ADC Europe 1956-1960 Espagne oㅜ 237).

7 Acta de la conversación entre Douglas Home y Franco, 30.V.1961 («Visit of the Foreign Secretary to Portugal and Spain. May 25-31 1961» PRO CAB 133-298).

8 EAM a SE, 23.III.1962 (NARA, RG59 Decimal Files, 1960-1963, 752.00/3-2362).
} 
concluido, en diciembre, con la ocupación mediante la fuerza de los últimos enclaves del denominado Estado da India (Goa, Damao, Diu) por el «pacifista» Nehru; había traído a un nuevo inquilino a la Casa Blanca - Kennedy - que, en su afán por ganar la carrera descolonizadora a los soviéticos, hacía causa común con todos los adversarios afroasiáticos del colonialismo portugués. Los ataques a Portugal, su abandono por los socios occidentales, la brutal expulsión de Goa, habían levantado de nuevo los sentimientos antiamericanos en España y habían llevado al régimen a cerrar filas con la causa de Portugal.

Pero la diplomacia franquista no era meramente el reflejo conservador, reactivo, de su inveterado anticomunismo, sino que también se abría por entonces a las nuevas realidades del mundo, marcadas sobre todo por los imparables vientos descolonizadores. Había incluso en el propio Caudillo una cierta valoración optimista de la evolución de la URSS, a la que Franco veía en una senda de modernización tecnológica, económica y social que, a su juicio, acabaría por derivar en cambios de naturaleza política. No, a largo plazo no era "pesimista» en este punto, le había dicho al secretario del Foreign Office en su entrevista de mayo del $61^{9}$. Tampoco su natural rechazo del régimen de Castro y sus temores respecto de la expansión del castrismo por Iberoamérica, impedían a España mantener relaciones con el régimen cubano y resistir a la política norteamericana de embargo a la isla ${ }^{10}$. En fin, la ofensiva democratizante de los primeros tiempos de la administración Kennedy, que, por la resistencia colonialista de Lisboa, tanto afectara a la dictadura portuguesa, no había lastimado al régimen español. Y, en todo caso, la visita del secretario de Estado, Dean Rusk, a España en diciembre de 1961 borraba cualquier suspicacia al respecto. En realidad —como se reconocía en Washington- «la retórica de la campaña (de las elecciones presidenciales), dirigida aparentemente contra todos los gobiernos autoritarios, no se ha (bía) traducido en actuaciones políticas» ${ }^{11}$.

Por mucho que se viera en los procesos de insurgencia anticolonialista la sombra alargada del comunismo - lo que era a todas luces cierto- la España de Franco no estaba dispuesta a resistir a los «vientos de la historia». Con cierta parsimonia y no sin altibajos contradictorios -en parte por la disparidad de posiciones en el interior del propio régimen - se había encaminado desde 1956, y sobre todo desde diciembre del 60, por la senda de la descolonización. Había muy buenas razones: nula sensibilidad colonialista en el país; pragmatismo en el régimen; el objetivo, cada vez más decidido, de recuperar Gibraltar; el deseo de conservar la tradición de entendimiento con el espacio del Tercer Mundo, que en los sesenta parecía marcar la agenda de las grandes cuestiones internacionales.

${ }_{9}$ Acta de la conversación entre Douglas Home y Franco, 30.V.1961 («Visit of the Foreign Secretary to Portugal and Spain. May 25-31 1961» PRO CAB 133-298).

10 EAM a SE, 3.III. 1964 y 7.VIII. 1964 (NARA, RG59 Decimal Files, 1964-1966, Politics 2262).

11 State Department's Bureau of Intelligence and Research a SE, 26.IX.1961 (NARA, L.B. Johnson Library, Austin-Tex - NSF National Intelligence Estimates «27 Spain and Portugal» box 5). 
Esa orientación descolonizadora debía convivir -y se logró- con el apoyo a las posiciones anticolonialistas de Lisboa, respaldadas sobre todo por decisión personal del propio Franco. En 1961, en el momento en que le estallan a Lisboa todos los demonios del envenenado problema mientras España daba pasos en el camino de la colaboración con Naciones Unidas para avanzar en el proceso descolonizador, viajaba a la capital portuguesa un alto funcionario de Exteriores ipara someter al placet de Salazar el cambio de rumbo de la diplomacia de Madrid! Y lo obtuvo. Es casi seguro que ni el ministro de Negocios Extranjeros, ni el presidente del Consejo, daban crédito a las promesas españolas de que hacerse representar en la Comisión para la Información sobre Territorios No Autónomos no significaría aceptación por España de que administraba ese tipo de territorios. Pero el argumento de que el precedente dilatorio español podía servir en el futuro a Portugal y, sobre todo, la idea de que a Lisboa le resultaría siempre útil para su defensa el apoyo de una España internacionalmente mejor situada, tenían indiscutible fuerza. En todo caso, ¿cómo hubiera podido exigir la diplomacia portuguesa que la española inmolara sus intereses en el fuego de los ajenos? ${ }^{12}$

Los equilibrios de la diplomacia de Madrid para apoyar a Portugal sin enfrentarse a los países Tercer Mundo ni contradecir su incipiente política descolonizadora, afloraban en las propias instrucciones de Franco, trasladadas por Castiella al representante en ONU: «me encarga Su Excelencia el Jefe del Estado sea V.I., de quien por cierto hizo un merecido elogio por su labor en Naciones Unidas, quien personalmente tome la palabra en defensa Portugal durante debate Angola (... )" Esa intervención debía ser "gallarda en relación con el país hermano, pero ponderada y sensata por lo que se refiere al problema general que se examina y a la situación crítica de la comunidad internacional». Y las líneas de intervención que se indicaban (por Castiella) al representante en ONU eran bien expresivas de ese equilibrio: España, creadora de pueblos, debía ser escuchada; la tesis de la descolonización violenta era típica estrategia del comunismo; la descoIonización tenía que asentarse sobre un proceso de preparación que estructurase socialmente a los pueblos y crease las necesarias élites dirigentes para un futuro que habría de madurar la historia - como había hecho España en América; la ONU vivía una grave situación porque muchos creían que debía dominar la demagogia. «Aparte de los títulos y razones de Portugal, no se contempla en este momento histórico más solución viable que la portuguesa. Es ésta la que puede garantizar el desarrollo de esta región africana y la realización de su completa personalidad dejando que sea la historia la que, en su día, permita ver las formas en que aquélla pueda tener su perfecto desarrollo" ${ }^{13}$.

Y, cuando la delegación española en ONU se aparta de la clara defensa de Portugal, es el propio Franco el que personalmente llama a Castiella para decirle que el apoyo debe ser «sin reticencias». Y Castiella le recuerda al delegado

12 Director General de Política Exterior a MAEE, abril 1961 (AMAE 8728-1).

13 MAEE al representante en Naciones Unidas, 17.I.1962, tel. 6 (AMAE, 8728-1). 
en ONU que el respaldo a Lisboa se basaba en la solidaridad ibérica, que pasaba por encima de otras consideraciones y no debía inscribirse en el escenario de un debate sobre si se estaba a favor o en contra el colonialismo. «Nuestra actitud con Portugal - recordaba haber ya escrito Castiella - obedece a una solidaridad amistosa, por encima de interpretaciones reglamentarias y legalistas de los textos, hacia un país tratado con injusticia, al que nos unen sentimientos de hermandad, además de los pactos escritos. No se trata de una postura a favor o en contra del equívoco concepto de colonialismo y así deben entenderlo los demás países »14. Los matizados argumentos en apoyo de Portugal pero sin criticar el fondo de la imparable corriente anticolonialista, ponían al descubierto la diversidad de los caminos internacionales ibéricos y la puesta al día de la ubicación exterior de la España franquista.

Ciertamente, en el cambio de década, España enfilaba un indiscutible camino de homologación diplomática y económica con un mundo en rápido proceso de cambio. Los informes diplomáticos se hacían eco abundante de procesos concomitantes: la modernización social y económica de España, su apertura internacional y el incremento de su presencia exterior. La solicitud de adhesión a la Comunidad Económica Europea, a principios de 1962, aparece en la documentación como el punto alto de una rápida transformación que, en tiempo record, había abierto el país a las corrientes y a los intereses internacionales, generando también un espíritu en exceso optimista respecto de las posibilidades del régimen por verse aceptado con normalidad en el exterior. El embajador británico, vuelto en 1960 a España, donde ya había desempeñado un cargo subalterno a principios de los años treinta, podía ponderar con larga perspectiva las importantes transformaciones operadas ${ }^{15}$, pero se hubiera asombrado más de haber sabido que las cotas de modernidad de 1935 no volvieron a alcanzarse hasta principios de los cincuenta. La petición de vincularse al club de los Seis era — según la embajada norteamericana - un jalón fundamental en la trayectoria española. España indicaba ahora de forma inequívoca «la dirección en la que desea viajar». "Aunque han sido los factores económicos los que han acelerado la decisión española de solicitar su asociación al Mercado Común Europeo, y quizá era inevitable desde un punto de vista económico, no es menos cierto que tanto desde un punto de vista político como económico este paso es uno de los seis acontecimientos más importantes del régimen de Franco desde la guerra civil. Si la solicitud de asociación es aceptada y se llevan a cabo los ajustes necesarios en el grado requerido, se puede prever que durante los próximos años tendrán lugar cambios de suma importancia para España» ${ }^{16}$.

La modernización de la economía y de la sociedad españolas suscitaban en todos los analistas diplomáticos el problema de la evolución política del país. Re-

\footnotetext{
14 MAEE a representante en Naciones Unidas, 20.XI.1962, tel. 127 (AMAE 8728-1).

15 EBM a FO, 2.I.1961, no 1 (PRO FO 371-160266).

16 EAM a SE, 23.III.1962 (NARA, RG59 Decimal Files, 1960-1963, 752.00/3-2362).
} 
sultaba claro que Franco no daba signos de mudanza, ni desvelaba sus intenciones de futuro en relación con una previsible restauración de la monarquía. Aún más, cuando en su entrevista de mayo de 1961, el ministro del Foreign Office, lord Home, se atrevió a preguntarle directamente si no «pensaba que se acercaba el momento en que sería posible introducir instituciones políticas», el Caudillo respondió con una «rápida negativa»; España — alegaba - ya tenía aquellas que le convenían, y los españoles no deseaban regresar al caos del sistema parlamentario de partidos ${ }^{17}$.

Era más que evidente que las mudanzas económicas habían generado un espíritu social de crítica bastante generalizada, con crecientes manifestaciones de agitación juvenil y de movilizaciones laborales, pero los informes norteamericanos creían que el poder de Franco estaba firmemente asentado y que la mayoría de los españoles se había «adaptado de una forma u otra al régimen, y hace tiempo que piensa que no hay sustituto para Franco". La clase capitalista valoraba el orden; los militares — que constituían la clave- eran leales al dictador; la policía y la censura constituían también instrumentos eficaces; la oposición era débil y estaba dividida; y, en fin, el temor al desorden y a la guerra civil evitaban que ese criticismo en auge desestabilizara al régimen ${ }^{18}$. No, a corto plazo, la modernización estaba reforzando la dictadura.

A largo plazo, ya era otra cosa. En general, los observadores extranjeros, no tenían duda de que el profundo cambio de la piel social y mental española resultaría incompatible con el mantenimiento de las caducas estructuras dictatoriales de poder. En un lúcido análisis sobre la España que se había encontrado a principios de los sesenta, el embajador británico no era capaz de responder a la enrevesada incógnita sobre el futuro desarrollo político, pero subrayaba la importancia del surgimiento de unas clases medias, antes casi inexistentes, que aportaban estabilidad, colmatando el viejo abismo entre ricos y pobres que había llevado a la revolución y a la dictadura. En todo caso, se mostraba «convencido de que la clave del futuro reside menos en lo político que en lo económico", porque lo segundo «por lo menos proporcionaría al país las escuelas y los profesores que darían a España la educación que tanto necesita y que es la única que, a largo plazo, hace posible la democracia» ${ }^{19}$. Antes o después -indicaban los informes americanos - la evolución socioeconómica habría inevitablemente de imponer el cambio político, «tanto si a Franco le gusta, como si no» ${ }^{20}$. Y el embajador francés era aún más rotundo y explícito: Franco, los falangistas, los «privilegiados» de la autarquía, que parecían resistirse a la llamada de Europa, tenían la batalla perdida: «Parecen ignorar —escribía- que los acontecimientos ya han desmentido su

17 Acta de la conversación entre Douglas Home y Franco, 30.V.1961 («Visit of the Foreign Secretary to Portugal and Spain. May 25-31 1961» PRO CAB 133-298).

18 Informe del Director de Inteligencia Nacional de Estados Unidos, 21.XI.1961 (L. B. Johnson Library, Austin-Tex-NSF box 5).

19 EBM a FO, 2.I.1961, no 1 (PRO FO 371-160266).

20 EAM a SE, 23.III.1962(NARA, RG59 Decimal Files, 1960-1963, 752.00/3-2362). 
pronóstico, que en las organizaciones internacionales y regionales a las que su país se ha adherido desde 1955 el «virus del liberalismo» ya ha contagiado a una parte de los dirigentes españoles y que el desarrollo del turismo ha contribuido a modificar profundamente la perspectiva de numerosos españoles. La nostalgia de la libertad se ha ido infiltrando así progresivamente al sur de los Pirineos, con la idea de que la discusión democrática de los problemas es más eficaz que las soluciones autoritarias" ${ }^{21}$.

Sin embargo, el cambio político solo se daría con Franco o después de Franco, nunca contra Franco. Puesto que el régimen no peligraba y el Caudillo no daba muestras de querer abandonar el poder, la idea de que tendría que aguardarse al momento de la sucesión biológica parecía firmemente asentada en los observadores extranjeros. Pero ¿cómo actuar entre tanto pensando en el momento de la transición? Y ¿cómo sería ésta? La cuestión era especialmente importante para los norteamericanos porque afectaba sobre todo a los intereses estratégicos de Washington en Península. Las especulaciones de los analistas estadounidenses partían de un principio irrenunciable: Estados Unidos debían conservar su presencia militar en España. De ahí, el interés por mantener relaciones estrechas con el régimen. Pero, al mismo tiempo, la diplomacia norteamericana tenía que asegurarse una posición confortable para el momento de la transición. Era por tanto necesario actuar con prudencia, conservando las buenas relaciones con la dictadura, pero deshaciendo la abusiva identificación con ella, que generalmente se atribuía a la política española de Washington, y abriéndose a discretos contactos con la oposición moderada y con los militares, que tenían en su mano el porvenir político del país. Atrapados entre sus prioritarios intereses defensivos y los obstáculos insuperables de democratización (cifrados en la voluntad de Franco y en su resistencia a adelantar el futuro) los americanos, como ellos mismos reconocían, no tenían mucho margen de maniobra ${ }^{22}$. Puesto que resultaba inútil -y hasta contraproducente - tratar de convencer al régimen de que cambiara, la principal aportación solo podía ser indirecta, estimulando la apertura económica española, propiciando el ingreso del país en los organismos internacionales, auspiciando el desbloqueo de las sociedades democráticas occidentales al ingreso de España en la OTAN y la CEE. ¿Y el desenlace? A la hora de prever la futura sucesión de Franco, la diplomacia norteamericana no parecía contemplar una plena democratización, al menos al principio. Incluso, si Franco moría sin haber nombrado sucesor, habría un gobierno militar que podría aceptar la entronización de una monarquía, siempre y cuando no fuera constitucional ${ }^{23}$. Y, en todo caso, la falta de tradiciones democráticas en España aconsejaba un cambio prudente y gradual, para evitar que la reacción de las fuerzas conservadoras malograse el proceso

${ }^{21}$ EFM a MAEF, 19.II.1963, no 227/EU (ADC Europe 1961-1968 Espagne ํㅜ 329).

22 Informe de la Sección de Europa Occidental del SE para Arthur M. Schlesinger, asesor de Presidente Kennedy, 28.III.1962 (NARA RG59 Lot Files 1955-1966, box 5).

${ }^{23}$ Informe del Director de la Inteligencia Nacional de Estados Unidos, 21.XI.1961 (NARA, L. B. Johnson Library, Austin-Tex-NSF box 5). 
democratizador: «Al considerar cuáles son los límites que los intereses de nuestra seguridad nacional hubieran podido imponer a nuestra libertad de acción, debemos mirar la situación en España. La democracia política ha sido un elemento poco común en la historia de España, repleta de fracasos de monarquías, dictaduras y repúblicas, así como de pronunciamientos militares y revoluciones violentas. En el presente, la dictadura de Franco ha impedido de manera efectiva el libre ejercicio de la práctica y los hábitos políticos, aunque también ha proporcionado al país un periodo de paz y estabilidad igualmente inusual, durante el cual España y sus gentes se han ido recuperando del agotamiento físico y emocional de la Guerra Civil. Esta falta de experiencia histórica fundamental en la dinámica de la negociación no violenta propia de la democracia política nos aconseja ser prudentes en lo que respecta a un cambio precipitado hacia las libertades políticas completas en España, que solamente pueden desarrollarse gradualmente y con mucho cuidado. La existencia de fuerzas conservadoras y reaccionarias aún poderosas en España es otra razón más para insistir en la prudencia, pues cualquier evolución en la esfera política que no fuera gradual, provocaría una fuerte oposición de aquéllas, contrarrestaría probablemente los cambios favorables que se han producido estos últimos años, y podría llevar a un nuevo enfrentamiento civil. La capacidad de maniobra de Estados Unidos en este ámbito es por lo tanto limitada, no sólo por las necesidades inmediatas de nuestra seguridad nacional, sino por factores importantes inherentes al pasado y presente político de España» 24 .

\section{AVANCES Y ESPERA (1962-1969)}

La solicitud de negociación con la CEE (1962) se percibió por las cancillerías de las grandes potencias occidentales como el natural colofón de un proceso de cambio internacional y de modernización interna, que debía propulsar definitivamente a España por la senda de la homologación con el escenario de las sociedades democráticas y capitalistas en que se ubicaba el país. El fundamental anclaje norteamericano se había renovado en 1963 sin problemas y con un «coste mínimo» para los Estados Unidos. La «declaración conjunta» sobre intereses mutuos de defensa no había comprometido más a la administración norteamericana con el régimen franquista, mientras que ahora, al contrario que en 1953, no se habían pactado contraprestaciones económicas. España ponía en marcha un Plan de Desarrollo con recursos propios, lo que, a juicio de embajador de Washington, representaba la mayoría de edad de los jóvenes y «relativamente liberales planificadores españoles» 25 .

\footnotetext{
${ }^{24}$ Informe de la Sección de Europa Occidental de SE para Arthur M. Schlesinger, asesor del Presidente Kennedy, 28.III.1962 (NARA RG59 Lot Files 1955-1966, box 5).

25 EAM a SE 3.III.1964 (NARA RG59 Subject Numerical Files 1964-1966 Politics 2262).
} 
Lo que ahora interesaba sobre todo a España era la respuesta de Bruselas a su demanda de asociación. Los americanos veían pros y contras de la integración española en la CEE: Estados Unidos perdería «influencia política y económica en España» y posiciones como "proveedor de las importaciones españolas», pero, por otra parte, comprendía cuán importante sería la vinculación a Europa para la deseable evolución interna del país: «A Estados Unidos - se escribía desde su embajada en Madrid - le interesa animar progresivamente a que España tenga unas relaciones más estrechas con las instituciones que se están desarrollando en el complejo económico y político de Europa Occidental, con el fin de ejercer mayor influencia sobre el gobierno español a favor de una liberalización política y económica gradual, que lleve a extender y fortalecer la base social en pos de la evolución hacia un sistema político basado en el pueblo y para ayudar a proporcionar un elemento de estabilidad durante el período crucial de transición que tenga lugar a la muerte de Franco ${ }^{26}$.

Temiendo un portazo de Bruselas, en febrero de 1963, el embajador francés en Madrid barajaba posibles alternativas de la dictadura española: refuerzo de la vinculación con los Estados Unidos, aproximación a los países del Este y a la URSS para contrarrestar la influencia norteamericana y el rechazo de Bruselas, neutralismo entre los bloques, apoyándose en clientes tradicionales del Mercado Común y en Gran Bretaña. Pero todo ello sería malo, para España y para la propia Europa, empezando por Francia. «Si no está claro - escribía- lo que España ganaría con estas opciones, distinto es lo que perdería y lo que perderían los demás países europeos, empezando por la vecina Francia. Son evidentes los inconvenientes para aquellos de un dominio americano, una infiltración soviética o un estado «no alineado» al sur de los Pirineos. Que tales hipótesis llegaran a convertirse en realidad significaría, por otra parte, para los españoles el fin de sus esperanzas, al señalar el final de una evolución política apenas comenzada y que sólo podría continuar en Europa y por Europa»27.

Cuando al cabo de dos años llegó la respuesta de Bruselas, era, como se esperaba, poco alentadora. El obstáculo político sería desde entonces insuperable mientras se mantuviera el régimen. Pero, como la CEE accedía a examinar los problemas «económicos» con España, la dictadura parecía poder salvar la cara y los liberales del gobierno respiraron frente a la presión de los autárquicos ${ }^{28}$. No obstante, Franco y los euroescépticos comenzaban a cansarse de esperar a la puerta de Europa ${ }^{29} \mathrm{y}$, probablemente, el régimen encontraba paliativo a su contrariedad dejándose arrullar por la política francesa, que ganaba fuerte ascendiente en España, sugiriendo una aproximación al eje París-Bonn y aplaudiendo, con

${ }^{26}$ EAM a SE 7.VIII.1964 (NARA RG59 Subject Numerical Files 1964-1966 Politics 2262).

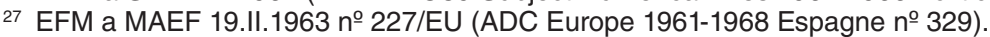

${ }^{28}$ EAM a SE, 7.VIII.1964 (NARA RG59 Subject Numerical Files 1964-1966 Politics 2262).

${ }_{29}$ Nota del MAEF para la Preidencia de la República, 1.X.1965 (ADC Europe 1961-1968 Espagne no 329). 
mayor o menor disimulo, los estridentes pronunciamientos de De Gaulle a favor de la «Europa de las patrias» y su veto al ingreso en la CEE de los británicos. Éstos llegaron a perder los nervios ante esa supuesta orientación española, al punto de que el embajador en Madrid se permitió una insolente queja ante el ministro Castiella, que se esforzaba en desmentir esas sospechas ${ }^{30}$.

A pesar del portazo de Bruselas, la política exterior española continuó en los años siguientes avanzando en la línea de la apertura y del protagonismo que la imprimía el ministro Castiella. Las relaciones con Portugal, cuya dictadura se fosilizaba y se resistía a alterar su encallecida resistencia a la presión anticolonialista, iban distanciándose, sobre todo desde el asesinato por la policía política portuguesa del general Humberto Delgado en 1965 — que motivó una seria gestión del embajador español ante el mismo Salazar, ordenada por el propio Franco-y por el malestar que vino a producir en Madrid la instalación en Lisboa del mando Iberlant de la OTAN, en 1967, sin que las autoridades portuguesas previnieran del caso a las españolas ${ }^{31}$. Aunque en realidad, como afirmaba el embajador británico en Lisboa, «las relaciones hispano-portuguesas brillan por su ausencia» 32.

El balance que realizaba la embajada norteamericana en Madrid de la política exterior española en 1967 era bastante positivo: el empeño de Gibraltar, que había cosechado éxitos en Naciones Unidas, imprimía una línea de congruencia descolonizadora, visible en la aceptación de la independencia de Guinea e incluso en la negociación con Marruecos sobre Ifni; con realismo y sin excesos, Madrid iba estableciendo relaciones con el bloque del Este; había demostrado, durante la crisis de Oriente Medio, la vigencia de su tradicional amistad con los árabes, pero también su sensibilidad humanitaria hacia el pueblo judío y cierta eficacia de su acariciada función de puente entre los occidentales y el mundo islámico, encargándose con éxito de los intereses norteamericanos en la RAU y en Mauritania; mantenía, en fin, una apreciable presencia en Iberoamérica, de alguna forma reconocida con la concesión a España de un status de observador en la Organización de Estados Americanos. Sin embargo, la OTAN y la CEE le seguían vedados por razones claramente políticas, lo que constituía-sobre todo en el caso de la segunda- el principal motivo de frustración ${ }^{33}$. Quedaban además pendientes las próximas negociaciones de renovación de los acuerdos defensivos con los Estados Unidos, que se anunciaban complicadas por los designios españoles de equilibrarlos. A finales de 1967 Castiella había expresado claramente al embajador francés la independencia de la diplomacia española respecto de los Estados Unidos. España difería de los puntos de vista de Washington en varios aspectos: Cuba, Oriente Medio, Vietnam. Era de interés mutuo el mantenimiento de los

30 EBM a FO, 1.II.1963, tel. 36 (PRO FO 371-169475).

31 EAM a SE, 1.II.1965 (NARA LBJL NSF-CF 204); EEL a MAEE, 14.V.1965, nํ 753 (Archivo Fundación Francisco Franco 3006-42); EBL a FO, 16.III.1967 (PRO FCO9-361); EAM a SE, 6.I.1968 (NARA RG59 Subject Numerical Files 1967-1969 Politics 2490).

32 Embajador británico en Lisboa a FO, 16.III.1967 (PRO FCO 9-361).

33 EAM a SE, 6.I.1968 ((NARA RG59 Subject Numerical Files 1967-1969 Politics 2490). 
acuerdos defensivos, pero éstos no deberían renovarse, sino revisarse y, desde luego, no habrían de implicar «sumisión» ${ }^{44}$.

Lo que, en cambio, entraba en vía muerta era la situación política interna, bloqueada por la manifiesta inmovilidad del Caudillo. Mientras que la «liberalización» avanzaba por la propia inercia de los cambios económicos y sociales, los resultados prácticos de la Ley Orgánica del Estado eran «decepcionantes». Franco persistía «en su actitud de no ceder el bastón de mando» y Europa no ayudaba nada: «es deprimente —escribía la embajada norteamericana en Madrid- Io poco que se ha modificado la oposición de los liberales izquierdistas europeos al acercamiento español a Europa» ${ }^{35}$. En 1967 los análisis norteamericanos consideraban que, mientras Franco viviera, España no cambiaría políticamente. Pero Franco seguía debilitándose. Y los españoles, mirando ya al calendario, hacían una lectura obvia: «el régimen de Franco se acerca (ba) a su final» ${ }^{36}$. La Inteligencia estadounidense, siempre preocupada por la conservación de las posiciones militares en suelo español, tendía a contemplar un «régimen sucesor (....) probablemente tan autoritario como el actual» ${ }^{37}$. Aún más, a principios de 1971, nada menos que el secretario de Estado, Rogers, expresaba al presidente Nixon la opinión de que, muerto Franco, el reinado de Juan Carlos podría ser efímero, o en todo caso mera cobertura para una continuidad autoritaria «bajo la mirada vigilante de los militares» 38 . Pero, preparando el futuro, la embajada no descuidaba «prudentes» contactos con los elementos liberales. No era fácil, por los recelos que provocaba entre los medios oposicionistas la vinculación de los Estados Unidos al régimen de Franco y por las críticas extendidas que suscitaba la guerra de Vietnam ${ }^{39}$. Pero, además ¿con quién tratar?; también en la oposición estaba habiendo un relevo generacional que tornaba complicado descubrir a los futuros interlocutores: «Algunos de los dirigentes más antiguos de la oposición están empezando a quedar marginados, e inevitablemente habrá un ascenso de nuevos líderes en el periodo indeterminado de tiempo que transcurra entre el momento presente y la fecha en la que comience el período de transición o «crisis». Esto es especialmente cierto en el ámbito de los trabajadores; estoy convencido de que los futuros dirigentes de los trabajadores españoles son probablemente jóvenes que ni nosotros ni los propios trabajadores han identificado todavía» ${ }^{40}$. En todo caso, la estrategia norteamericana persistía en un objetivo prioritario: conservar su presencia militar en España; y en una táctica flexible y prudente: alentar indirectamente la democratización española favoreciendo la vinculación del país a las instituciones europeas y atlánticas; preservar las buenas relaciones con el régimen; y «a largo

${ }^{34}$ EFM a MAEF, 18.XI.1967, n 656/660 (ADC Europe 1961-1970 Espagne no 331).

35 EAM a SE, 9.V.1968 (NARA RG59 Subject Numerical Files 1967-1969 Politics 2493).

36 Director de Inteligencia Central a SE, 27.I. 1967 (NARA, LBJ Library NSF Box 5); EAM a SE, 30.VI.1967 (NARA RG59 Subject Numerical Files 1967-1969 Politics 2493)

37 Director de Inteligencia Central a SE, 27.I. 1967 (NARA LBJ Library NSF Box 5).

38 SE a presidente Nixon, 22.I.1971 (NARA NS-NSCF Harold Middle East Neg. Files 1189).

39 EAM a SE, 30.VI.1967(NARA RG59 Subject Numerical Files 1967-1969 Politics 2493.

40 EAM a SE, 26.VII.1965 (NARA RG 59 Lot Files 1955-1966, box 1). 
plazo, en la medida de lo posible sin poner en riesgo nuestra posición actual, desarrollar relaciones discretas con grupos e individuos dentro y fuera del gobierno que podrían tener voz a la hora de configurar políticas futuras y que podrían influir en una evolución democrática de España» 41.

\section{3. ÚLTIMO IMPULSO Y COLAPSO (1969-1975)}

El año 69 asistió a dos cambios importantes que habrían de dar nuevo impulso durante algún tiempo a la posición exterior española: la proclamación oficial del Príncipe Juan Carlos como sucesor de Franco y el relevo de gobierno, en el mes de octubre, con la entrada en Exteriores del dinámico López Bravo, sustituyendo al agotado Fernando Castiella, definitivamente encallado en Gibraltar y en las negociaciones para la renovación de los acuerdos con los Estados Unidos. El embajador francés valoraba como baza de indudable utilidad política la persistente discreción del Príncipe - seguramente mal comprendida por la opinión-que no podía enajenarse ninguna de las fuerzas llamadas a actuar en el inmediato futuro ${ }^{42}$. Los británicos reconocían el cambio de ambiente en las relaciones con España que había supuesto el nuevo estilo dialogante y pragmático de López Bravo. El país iba saliendo definitivamente de su "Tibet político»; estaba impulsando aún en vida de Franco "actitudes más modernas y abiertas", en contraste con lo acontecido en Portugal bajo Salazar. Los funcionarios del Foreign Office se preguntaban si no estarían "perdiendo oportunidades a la vista del nuevo escenario» ${ }^{43}$.

En efecto, a lo largo del año 70 la política exterior española cosechó éxitos muy notables: relanzamiento del diálogo sobre Gibraltar; acuerdo económico con la CEE (junio); acuerdo militar con Francia (22 de junio); acuerdo de defensa con los Estados Unidos (6 de agosto), éstos últimos valorados muy positivamente, en lo que representaban para la política externa española, tanto por el secretario de Estado norteamericano, Kissinger ${ }^{44}$, como por el Ministerio de Exteriores francés, que se expresaba así: «la posición militar y política en que se encuentra España en virtud de los acuerdos firmados con Francia y con Estados Unidos es bastante favorable. El nuevo acuerdo hispano-estadounidense respeta más que el anterior la soberanía española; el acuerdo firmado por el señor Debré el 22 de junio viene a equilibrar lo que habría tenido de oneroso una cooperación militar demasiado exclusiva con Washington y subraya, muy oportunamente para la diplomacia de España, su preocupación por mantener la independencia. Además, como se ha visto, el acuerdo firmado con Washington abre una vía lateral, discreta pero que puede ser eficaz, de acercamiento y de cooperación concreta con la OTAN. Por lo tanto, Madrid se ha procurado un dispositivo bastante equilibrado que le

\footnotetext{
41 EAM a SE, 21.III.1969 (NARA RG59 Subject Numerical Files 1967-1969 Politics 2493).

42 EFM a MAEF, 6.VIII.1969 (ADC Europe 1966-1970 Espagne ํㅜ261).

43 EBM a FO, 31.XII.1969 (PRO FCO 9-1279).

44 De Kissinger a Nixon, 1.X.1970 (NARA Nixon Project NPMP NSC 468).
} 
permite, al parecer, esperar y ver venir las cosas ${ }^{45}$. Incluso parecía relanzarse la recurrente idea de un pacto de seguridad del Mediterráneo Occidental, ahora de clara factura «neutralista», en línea con la política del último Castiella, y en general con las veteranas aspiraciones de la diplomacia española a una proyección internacional del país más activa y autónoma ${ }^{46}$. Y, entre tanto, se habían impulsado enormemente las relaciones con la URSS y con los países del Este; proseguía con dinamismo el entendimiento con el bloque afroasiático y las relaciones amistosas con los países árabes; Madrid daba pronta y positiva respuesta (8 de julio 69) a la celebración de la Conferencia de Seguridad Europea en Helsinki ${ }^{47}$. El estrecho entendimiento franco-español llegaba incluso a provocar la alarma —no del todo compartida por el Foreign Office- del embajador británico en Madrid, por las ventajas económicas francesas en España, mientras que los ingleses habían estado en la inopia, «nadando en las virtuosas pero autocomplacientes aguas de la desaprobación ideológica» ${ }^{48}$.

Pero el redoblado impulso exterior español no podía ya sobrepasar el techo posible de una inercia de importante presencia exterior y de constante optimización de los recursos diplomáticos, «técnicos», incapaces sin embargo de superar los límites infranqueables de la naturaleza política del régimen. Aún más, el contraste entre la razonable importancia intrínseca del país, sus naturales aspiraciones, la propia calidad del trabajo de su sector exterior, y esas inapelables limitaciones políticas dictadas por la naturaleza del régimen, tornaban especialmente amargo el rechazo exterior, tan visible en la recta final de la dictadura franquista. Así quedó demostrado a finales de ese mismo año 70 con la celebración de los juicios de Burgos contra terroristas de la ETA, que provocaron una ola de repudio internacional contra la España de Franco y deterioraron las fundamentales relaciones con Francia ${ }^{49}$. Y, aunque la prudencia del presidente Pompidou, consciente de la convergencia de intereses de ambas naciones ${ }^{50}$, contribuyó muy pronto a despejar el panorama inmediato, tratando de «mantener la continuidad de nuestra política», las relaciones transpirenaicas ya nunca recuperarían la situación anterior: los incidentes contra las mercancías españolas de tránsito por Francia, la posición de París contraria a que España accediese a las «preferencias generalizadas» que concedía la CEE y, sobre todo, el contencioso suscitado por la presencia de terroristas de ETA en territorio fronterizo francés, mantuvieron una relación entre quisquillosa y tensa ${ }^{51}$.

\footnotetext{
45 Informe, sin autor ni destinatario, del Minsterio francés de Asuntos Extranjeros, 20.X.1970 (ADC Europe 1966-1970 Espagne n우 331).

46 Subsecretario de Asuntos Exteriores a Embajador de España en Portugal, 8.IV.1970 (AMAE 6636).

47 EAM a SE, 21.XI.1970 (NARA RG59 Subject Numerical Files 1970-1973 Politics 2599); Nota de la EFM, 9.XII.1970 (ADC Europe 1961-1970 Espagne no 328).

48 EBM a FO, 24.XI.1970 (PRO FCO 9-1287); Minuta del Departamento de Europa del Sur, FO, 11. XII.1970 (PRO FCO 9-1287)

49 Nota del MAEF, 1.VI.1971 (ADC Europe 1971-Juin 1976 Espagne no 443).

50 Nota del MAEF, 21.III.1974 (ADC Europe 1961-Juin 1976 Espagne no 445).

51 Nota del MAEF, 1.VI.1971 (ADC Europe 1971-Juin 1976 Espagne no 443).
} 
Los años 72 y 73 revelan con claridad la dimensión inapelable de los obstáculos políticos que se interponían en el desarrollo de la presencia internacional española. En la cuestión dominante y altamente simbólica de la relación con la CEE, la diplomacia española no podía ir más allá de una revisión económica, dictada por la ampliación comunitaria, del acuerdo de 1970. Ninguna concesión de tipo político, debido a la propia naturaleza del régimen, agravada — según el embajador francés- por el «total inmovilismo político que reina en Madrid» 52 . Era inútil que López Bravo se empeñase en insistir en que la unidad europea no debía construirse sobre «uniformidad y falso igualitarismo», sino que debía asumir «la variedad de los pueblos que la componen y la necesidad de respetar sus particularidades propias» ${ }^{53}$. Si en algún momento cupo hacerse ilusiones, especulando con los más teóricos que efectivos apoyos de Francia o Alemania, en el último tramo del franquismo ya no había dudas de que la Europa política quedaba fuera del alcance de España. De hecho, como muy bien percibía a finales del 73 el embajador de Francia, las iniciativas aperturistas de la diplomacia española en los últimos años habían «puesto de manifiesto los límites que los países interesados querían poner a sus relaciones con Madrid, lo que ha originado un sentimiento de frustración y la conciencia de un ostracismo al que los avances no conseguían poner fin». Ese sentimiento de malhumor últimamente «ya no se limitaba a los círculos gubernamentales u oficiales, sino que era perceptible en los ambientes de la administración, entre aquellos que, en general, constituyen la opinión» 54 .

Por entonces, el asesinato del presidente del Gobierno, Carrero Blanco, abría definitivamente, y ahora de forma inmediata, la gran incógnita sobre la transición española. En el exterior, todo quedaba pendiente de lo que el futuro próximo le reservase a España. En los dos últimos años del franquismo el frenazo en el exterior fue más que visible. La revisión del acuerdo con la CEE no avanza; las pretensiones de Madrid a un «vínculo más oficial» con la OTAN, invocando la modalidad de la inserción francesa, sólo encuentran en París una promesa de apoyo «hasta cierto punto». Y en el Sahara, el referéndum de autodeterminación, que Madrid postula, convive mal con los intereses — que tampoco puede desconocer- de los poderosos vecinos africanos y de la tradicional política norteafricana de la diplomacia francesa ${ }^{55}$. Francia, por tantas razones, amigo necesario y enemigo inconveniente, deja de ser la «puerta de Europa» que quería López Bravo ${ }^{56}$ para devenir en el insidioso adversario, experto en amargar la fiesta al vecino del sur; y, más aún, desde que el razonable Pompidou, fallecido en abril de 1974, fuera reemplazado en el Elíseo por el fatuo Giscard d'Estaing ${ }^{57}$. El gran contencioso en que se sustancia la crisis políti-

52 EFM a MAEF, 6.XII.1972, no 652/DE (ADC Europe 1971-Juin 1976 Espagne nํ 427).

53 EFM a MAEF, 3.V.1972, no 298/EU (ADC Europe 1971-Juin 1976 Espagne nำ427).

54 EFM a MAEF, 14.XII.1973, tel. 801/10 (ADC Europe 1971-Juin 1976 Espagne no 428).

55 Nota del MAEF, 28.V.1975 (ADC Europe 1971-Juin 1976 Espagne no 446).

56 Nota del MAEF, 1.VI.1971(ADC Europe 1971-Juin 1976 Espagne no 443).

57 Nota del MAEF sobre las relaciones franco-españolas 13.I.1975 (ADC Europe 1971-Juin 1976 Espagne no 446). 
ca de las relaciones hispano-francesas desde finales de 1970 y, sobre todo, tras el asesinato del almirante Carrero, en diciembre de 1973, es la descarada impunidad con la que actúan en territorio francés los asesinos de ETA ${ }^{58}$. Serán inútiles cuantas gestiones realice el gobierno español para que París le entregue a los terroristas y liquide el persistente santuario francés donde éstos se mueven a sus anchas. La República se atiene al «carácter político del asunto» y a las leyes de la vieja democracia francesa que, siendo «político el asunto», protegían a los refugiados. Nada más natural cuando la sangre la ponían otros y, además, el régimen franquista estaba en sus últimas. Que para Francia el asunto era meramente «político» no cabía duda. Una nota del Ministerio de Asuntos Extranjeros lo explicaba muy bien, por doble partida. Primero, la paz propia: «Pese a que nos interesa evitar que la agitación alcance a las provincias vascas francesas, hemos adoptado medidas de alejamiento en Francia, más o menos eficaces, contra determinados refugiados inmediatamente después del atentado de diciembre de 1973». Además, ya no convenía apostar demasiado en un régimen en estado de liquidación: «debido a la precariedad del poder actual, sería sin duda preferible evitar sustentar sobre él una política amplia de desarrollo de las relaciones franco-españolas reservando al sucesor del general Franco este esfuerzo y nuestro apoyo»59.

Naturalmente, los dos años finales del régimen de Franco atraen especialmente la atención de las potencias occidentales sobre la incertidumbre del inmediato futuro político de España, que condiciona, como hemos visto, el desarrollo de sus intereses internacionales. Los británicos produjeron análisis muy clarividentes. Ante la crisis abierta por el asesinato de Carrero, el Foreign Office contemplaba un buen augurio de futuro en la «resistencia y solidez» mostrada por las instituciones y en el predominio de los elementos «moderados» sobre el «sector más reaccionario de las fuerzas armadas ${ }^{60}$. Y, un año más tarde (diciembre 1974), en un inteligente análisis sobre el futuro de España, el embajador británico en Madrid se mostraba optimista. No creía que, tras la desaparición de Franco, la partida se jugase entre las posiciones extremas de derecha e izquierda. El régimen y el Movimiento estaban ya muertos. Cierto que España tenía que aprender la lección de Portugal, pero «ambos países y ambos pueblos no pueden ser más diferentes». En Portugal no había «una amplia clase media (...) que tiene mucho que perder». El ejército español tampoco había tenido que «soportar una guerra colonial». Y, hasta se atrevería a aventurar que, pronto desaparecida la «vieja guardia» que había participado en la guerra civil y en la División Azul, «la mayor parte de los militares (eran) reformistas relativamente moderados». Él apostaba por una clara evolución hacia la democracia. Con ese fin, había entrado en contacto no sólo con las diversas tendencias de la «oposición oficial», sino con esa otra constituida por

58 Nota del MAEF, 21.III.1974 (ADC Europe 1971-Juin 1976 Espagne nํ445).

59 Nota del MAEF, 29.VII.1975 (ADC Europe 1971-Juin 1976 Espagne no 428); Nota del MAEF, 19.IX. 1975 (ADC Europe 1971-Juin 1976 Espagne no 446).

60 Embajador de Francia en Londres al MAEF, 10.I.1974, nํ31/EU (ADC Europe 1971-Juin 1976 Espagne $\mathrm{n}^{\circ}$ 433). 
«muchos elementos que todavía trabajan dentro del sistema, especialmente entre las generaciones más jóvenes, que pueden muy bien ser descritas como opositores de facto». Y recomendaba cultivar a los militares, sobre todo a los jóvenes, porque «antes o después, los militares, especialmente en el ejército de tierra, desempeñarán un papel decisivo, ya sea por la acción, la pasividad o una mezcla de ambas» ${ }^{61}$. Era imposible más atinada previsión.

También extremadamente lúcido, sobre las dificultades de su situación y la dramática prudencia con que la estaba asumiendo, era el futuro rey en conversación, por las mismas fechas (noviembre de 1974), con el embajador de Francia que, como el arrogante Giscard, parecía entender mucho menos que su colega inglés la coyuntura española. Cuando, ante las quejas de Juan Carlos sobre la resistencia del Caudillo a cualquier cambio, el diplomático le sugiere que «debía desmarcarse del régimen» para no degradar políticamente su imagen, el Príncipe replica: «¿Qué hago? ¿Me marcho? Eso no arreglaría nada. He expresado mis sentimientos públicamente en dos discursos recientes y con mi actitud manifiesto siempre que puedo mi desacuerdo con el inmovilismo. Pero no puedo ir demasiado lejos, so pena de pasar a la oposición oficial. Sé que se me considera una marioneta. Sé también que el señor Giscard d'Estaing ha dicho "España está perdida. Juan Carlos está liquidado". Conozco lo bastante la terminología francesa como para no ver en estas palabras un comentario desagradable respecto a mi persona. Tiene algo de salida de tono. Pero, vistas desde dentro, las cosas son más difíciles de lo que se pueda pensar en el extranjero» 62.

Las ejecuciones de finales de septiembre de 1975 pusieron cruel término al régimen de Franco que, como explicaba una nota del Ministerio francés de Extranjeros concluía «su largo reinado en el callejón sin salida de una represión brutal» ${ }^{63}$. La protesta internacional fue contundente, con manifestaciones en todas partes y llamada de embajadores. La moderación corrió a cargo de británicos, alemanes ${ }^{64} \mathrm{y}$, naturalmente, de la administración norteamericana, siempre más pragmática porque tenía más que perder ${ }^{65}$.

Nadie dudaba de que el interés de todos, españoles o no, era que la España sin Franco desde el 20 de noviembre de 1975 se encaminase hacia un sistema plenamente democrático. Pero ¿cómo avanzar? Las alternativas contempladas por

61 EBM a FO, 10.XII.1974 (PRO FCO 9-2087).

" «Foutu» en el original.

62 Nota del EFM, 16.XII.1974 (ADC Europe 1971-Juin 1976 Espagne nํ446).

63 Nota del MAEF, 19.IX.1975 (ADC Europe 1971-Juin 1976 Espagne no 446).

64 Embajada de Francia en Londres a MAEF, 14.X.1975, tel. 2340/41 (ADC Europe 1971-Juin 1976 Espagne n 433); Embajador de Francia en la RFA a MAEF, 4.XI.1975 (ADC Europe 1971-Juin 1976 Espagne no 435).

65 Embajada de Francia en Washington a MAEF, 29.IX.1975, tel. 7567/71 (ADC Europe 1971Juin 1976 Espagne no 431). 
la administración norteamericana ${ }^{66}$ tienen el interés de resumir las dos vías posibles: la de una evolución "gradual», «paso a paso», con «mesura», que evitase dar pábulo a los extremismos de izquierda o derechas y excluyese por supuesto del proceso a los comunistas; la de un proceso de apertura, rápido y decidido, un «salto político hacia el centro", sin exclusiones, que legitimaría y entregaría las riendas del país a Juan Carlos, suponiendo que la «vieja guardia franquista» no se atrevería a actuar contra un monarca designado por el Caudillo. La opción primera era la canónica, la que tradicionalmente había contemplado Washington, la que, suscrita por el secretario de Estado Kissinger, constituía también ahora doctrina oficial. La segunda estaba muy extendida y gozaba de predicamento en el propio Departamento de Estado. Sería esta última la que, despejado el obstáculo de Carlos Arias, vendría a llevar a cabo el nuevo rey con el auxilio precioso de Suárez.

Ciertamente la cuestión política había condicionado y lastrado la proyección exterior española. Pero la época franquista no había sido un paréntesis; no había pasado en balde. La economía se había desarrollado; la sociedad se modernizó; el país - dirigido por unas élites preparadas - quedó incorporado de forma bastante intensa al escenario de las sociedades occidentales, al tiempo que consolidaba como estructurales las llamadas «políticas sustitutorias»: superando definitivamente el tradicional «contencioso» ibérico ${ }^{67}$ y abriéndose con persistente inteligencia al Tercer Mundo, sobre todo en su dimensión iberoamericana y árabe. La España de Franco podía tener - y de hecho tenía - su marcha internacional limitada, pero ni había estado parada, ni era en el «concierto» exterior quantité négligeable.

\section{ABREVIATURAS MÁS FRECUENTES}

ADC: Archives Diplomatiques Français (La Courneuve).

EAM: Embajada / Embajador de los Estados Unidos en Madrid.

EBM: Embajada / Embajador del Reino Unido en Madrid.

EFM: Embajada / Embajador de Francia en Madrid.

FO: Foreign Office.

MAEF: Ministère des Affaires Étrangères (Paris).

MAEE : Ministerio de Asuntos Exteriores (Madrid).

NARA: National Archives and Record Administration.

PRO: Public Record Office.

SE: Secretario/ Departamento de Estado (Washington).

66 EFM a MAEF, 6.XI.1975 (Ibídem); de Wreatham E. Gatheight (Grupo de Trabajo de Planificación de Contingencia NSC del Departamento de Estado) al Jefe de Acciones Especiales de Washington del NSC, 7.XI.1975 (NARA RG 59 Nixon Project Consejo Seguridad Nacional 235); Embajada de Francia en Washington a MAEF, 23.XII.1975, no 53/DA/EU (ADC Europe 1971-Juin 1976 Espagne no 431).

67 La prueba de ello fue la voluntad de convivencia amistosa a pesar de las naturales dificultades generadas por la revolución portuguesa (Nota del MAEF, 19.VI.1975 y EFM a MAEF, 14.I.1976. —ADC Europe 1971-juin 1976 Espagne no 437). 
